\title{
High-resolution characterisation of austenitic stainless steel in PWR environments: effect of strain and surface finish on crack initiation and propagation.
} DOI:

10.1007/978-3-319-67244-1_53

\section{Document Version \\ Accepted author manuscript}

Link to publication record in Manchester Research Explorer

Citation for published version (APA):

Pimentel, G., Tice, DR., Addepalli, V., Mottershead, K. J., Burke, M. G., Scenini, F., Lindsay, J., Wang, Y. L., \& Lozano-Perez, S. (2018). High-resolution characterisation of austenitic stainless steel in PWR environments: effect of strain and surface finish on crack initiation and propagation. In Proceedings of the 18th International Conference on Environmental Degradation in Nuclear Power Systems - Water Reactors (pp. 829-847) https://doi.org/10.1007/978-3-319-67244-1_53

\section{Published in:}

Proceedings of the 18th International Conference on Environmental Degradation in Nuclear Power Systems Water Reactors

\section{Citing this paper}

Please note that where the full-text provided on Manchester Research Explorer is the Author Accepted Manuscript or Proof version this may differ from the final Published version. If citing, it is advised that you check and use the publisher's definitive version.

\section{General rights}

Copyright and moral rights for the publications made accessible in the Research Explorer are retained by the authors and/or other copyright owners and it is a condition of accessing publications that users recognise and abide by the legal requirements associated with these rights.

\section{Takedown policy}

If you believe that this document breaches copyright please refer to the University of Manchester's Takedown Procedures [http://man.ac.uk/04Y6Bo] or contact uml.scholarlycommunications@manchester.ac.uk providing relevant details, so we can investigate your claim.

\section{OPEN ACCESS}




\author{
$18^{\text {th }}$ International Conference on Environmental Degradation in Nuclear Power Systems - Water \\ Reactors \\ Portland, Oregon, USA, 13-17 August 2017
}

\title{
High-resolution characterisation of austenitic stainless steel in PWR environments: effect of strain and surface finish on crack initiation and propagation.
}

\author{
G. Pimentel ${ }^{1}$, D.R. Tice ${ }^{2}$, V. Addepalli' ${ }^{2}$, K.J. Mottershead ${ }^{2}$, M.G. Burke ${ }^{3}$, F. Scenini ${ }^{3}$, J. Lindsay ${ }^{3}$, Y.L. Wang ${ }^{3}$ \\ and S. Lozano-Perez ${ }^{1}$
}

${ }^{1}$ University of Oxford, Department of Materials, Parks Road, Oxford, OX1 3PH, UK

${ }^{2}$ AMEC Foster Wheeler, Walton House, Birchwood Park, Birchwood Warrington, Cheshire, WA3 6GA, UK

${ }^{3}$ University of Manchester, Material Performance Centre, Manchester, UK

\begin{abstract}
Initiation and propagation of cracks under simulated primary water conditions and different slow strain rates have been studied for an austenitic 304-type stainless steel. Two surface finishes were used to better understand the conditions that trigger stress corrosion cracking (SCC).

The main objective is to identify the mechanism(s) that govern the initiation and propagation of SCC and the influence of microstructure. Crack morphology, stress localisation and local chemical composition were characterized for all samples studied. The characterization methodology includes scanning electron microscopy (SEM), 3D focused ion beam (FIB), Transmission Kikuchi Diffraction (TKD), and analytical scanning transmission electron microscopy (STEM).
\end{abstract}

\section{Keywords}

Stress Corrosion Cracking (SCC), Slow Strain Rate Test (SSRT), Transmission Kikuchi Diffraction (TKD), Electron Energy Loss Spectroscopy (EELS)

\section{INTRODUCTION}

Stainless steel alloys, like austenitic type 304, are often used for structural components in the primary circuit of fission reactors due to their excellent behaviour under high-temperatures and corrosive environments [1]. However, despite their corrosion resistance, the combination of stress in a corrosive environment, during long operation periods, can, under some conditions, trigger the appearance of microscopic cracks that penetrate into the material (known as stress corrosion cracking (SCC)) [2], [3]. Even though SCC has been widely studied over the past two decades [1][4][5], there is still limited understanding of the mechanisms that govern the initiation and propagation of these cracks and, although a range of models have been proposed [6], still there is no agreement on a common and general model.

Since intergranular oxide penetrations were observed, many of these previous SCC studies were based on internal oxidation or oxygen diffusion ahead of the crack tip [7][8] and rely on the fact that oxygen locally diffuses at the same rate or faster than the crack growth rate and that the oxides forming are more brittle than the metal matrix. Therefore, a variety of electron microscopy methods have been used in order to analyse oxide chemistry, crack morphology and local changes around the crack tip [9][10][11]. However, most studies do not take into account crystallographic aspects such as grain misorientation, local plastic deformation and strain localization in the area surrounding the crack tip. In this effort, transmission Kikuchi diffraction (TKD) has been proven to be very beneficial in revealing the extent of the strain concentration around the crack tips of 316 stainless steel and its effect on SCC [12][13]. Therefore, an in-depth characterization effort providing information at high resolution and $\mathrm{nm}$ length scales combining chemical analysis Electron Energy Loss Spectroscopy (EELS) and Energy-dispersive X-ray spectroscopy, (EDX) and local stress and strain measurements (TKD) could contribute to solve some of the remaining questions. This is the focus of the current work. Moreover, since SCC propagation depends on multiple parameters (such as test temperature, material composition and water chemistry) two specimens of 304 stainless steel under different slow strain rate conditions and one specimen tested under constant load will be compared in order to study the effect that effective strain and microstructure (separate from all other factors) have on SCC. 


\section{MATERIALS AND METHODS}

The material used for this work is an austenitic 304 stainless steel. Its chemical composition is shown in Table 1.

Table 1. Chemical Composition (wt \%) of the alloy 304SS

\begin{tabular}{|c|c|c|c|c|c|c|c|c|c|c|c|c|}
\hline $\mathbf{A l}$ & $\mathbf{S i}$ & $\mathbf{T i}$ & $\mathbf{V}$ & $\mathbf{C r}$ & $\mathbf{M n}$ & $\mathbf{F e}$ & $\mathbf{C o}$ & $\mathbf{N i}$ & $\mathbf{C u}$ & $\mathbf{N b}$ & $\mathbf{M o}$ & $\mathbf{S n}$ \\
\hline$<0.05$ & 0.36 & 0.36 & 0.09 & 18.34 & 1.86 & 70.08 & 0.08 & 7.93 & 0.29 & $<0.05$ & 0.33 & 0.08 \\
\hline $\mathbf{W}$ & $\mathbf{P}$ & $\mathbf{M g}$ & $\mathbf{C a}$ & $\mathbf{Z n}$ & $\mathbf{Z r}$ & $\mathbf{H f}$ & $\mathbf{T a}$ & $\mathbf{P b}$ & $\mathbf{C}$ & $\mathbf{S}$ & $\mathbf{N}$ & $\mathbf{O}$ \\
\hline 0.05 & 0.023 & $<0.05$ & $<0.05$ & $<0.05$ & $<0.05$ & $<0.05$ & $<0.05$ & $<0.05$ & 0.029 & 0.004 & 0.069 & 0.028 \\
\hline
\end{tabular}

The material was then forged to a $20 \%$ reduction in the temperature window $170-360{ }^{\circ} \mathrm{C}$ in order to suppress any martensitic transformation induced by strain. Then, three flat tensile samples (with a gauge length of $24 \mathrm{~mm}$ and a cross section of $3.5 \times 1 \mathrm{~mm}$ ) were extracted from the bulk material in the $\mathrm{S}-\mathrm{L}$ orientation since previous experience had shown this to be the most susceptible orientation for cracking. Each tensile sample was prepared in order to have two surface finishes, one side was ground with 600 grit SiC paper and the other side was subsequently ground with $600,800,1200,2400$ and $4000 \mathrm{SiC}$ grit paper, polished with 3 and $1 \mu \mathrm{m}$ water based polishing suspension and a final polish was performed for a minimum of 30 min with a $60 \mathrm{~nm}$ oxide polishing suspension (OPS).

In order to induce SCC, the samples were exposed in a continuously refreshed autoclave at $300{ }^{\circ} \mathrm{C}$ to simulated PWR primary coolant, i.e. high purity water with $2 \mathrm{ppm}$ of lithium (as lithium hydroxide) and $30 \mathrm{cc} / \mathrm{kg}$ of hydrogen. Two of the samples (SSRT-T1 and SSRT-T2) were tested under slow strain rate tensile (SSRT) conditions and the third sample $(\mathrm{C} 3 \mathrm{R} 2 \mathrm{C} 1)$ was subjected to a constant load test. The slow strain rate samples were loaded at $10^{-6} \mathrm{~s}^{-1}$ up to close to yield and subsequently at a much lower strain rate. The tests were interrupted after a few percent plastic strain as shown in Table 2 .

Table 2. SSRT and constant load test conditions.

\begin{tabular}{|c|c|c|c|c|c|}
\hline Sample & Loading Strain Rate $\left(\mathrm{s}^{-1}\right)$ & Test Strain rate $\left(\mathrm{s}^{-1}\right)$ & Load $(k N)$ & Test Duration (h) & Strain \\
\hline SSRT-T1 & $10^{-6}$ & $2.5 \times 10^{-8}$ & --- & 500 & $5 \%$ \\
\hline SSRT-T2 & $10^{-6}$ & $1.0 \times 10^{-8}$ & --- & 900 & $3 \%$ \\
\hline C3R2C1 & $10^{-5}$ & --- & 2.8 & 800 & $1.6 \%$ \\
\hline
\end{tabular}

After the tests, OPS and 600 grit surfaces were analysed on each sample with a variety of techniques in order to characterise oxidation depths, cracks, chemical composition, local strain/stress and defects relative to microstructure.

SEM examination was performed in a Zeiss Merlin operating at $5-10 \mathrm{kV}$ and $8.5 \mathrm{~mm}$ working distance (WD). FIB milling was performed on a Zeiss NVision 50. 3D-FIB slicing was performed with $30 \mathrm{kV} \mathrm{Ga}^{+}$and $700 \mathrm{pA}$ while for SEM image acquisition $5 \mathrm{kV} \mathrm{e}^{-}$was used. Post-processing of images (tilt corrected) was performed using Gatan's Digital Micrograph (DM) for image stacking, alignment and drift-correction [14]. AVIZO 6.0 was used for phase segmentation (based on pixel intensity) and 3D image reconstruction. FIB was also used to prepare TEM foils containing crack tips. EELS and EDX spectra were acquired with a Jeol ARM200F Cold Field Emission Gun (CFEG) equipped with a Gatan Image Filter (GIF) [15] and a 100 $\mathrm{mm}^{2}$ Centurion EDX detector. The voltage used was $200 \mathrm{keV}$ and EELS acquisitions in STEM mode were performed with an incident angle of $20 \mathrm{mrad}$ and a collection angle of $40 \mathrm{mrad}$. Multivariate Statistical Analysis (MSA) was applied for denoising the EELS data and for identifying relevant trends [16][17]. Transmission Kikuchi diffraction (TKD) maps were collected at various cracks in order to identify local strain/stress. TKD patterns were generated on TEM thin foils at an acceleration voltage of $20 \mathrm{kV}, 5 \mathrm{~mm}$ WD and collected using a Nordlys Max EBSD detector (Oxford Instruments) mounted in a FIB-SEM Zeiss crossbeam 540. The indexation of the Kikuchi lines and the determination of the orientations were done with Oxford Instruments Aztec and analysed with CHANNEL5 software. The results were represented by means of local misorientation (KERNEL) and average misorientation maps.

\section{RESULTS}

\subsection{Baseline characterisation}

A baseline characterisation of the as-received material has been done including grain size, $\delta$-ferrite content and inclusion identification. The average grain size for austenite and delta ferrite and delta ferrite content were obtained via EBSD from different regions of the material. A grain was then defined as an orientation change 
which exceeded $10^{\circ}$ (boundaries with a misorientaion of $60^{\circ}$ were excluded from the calculations in order to remove twin boundaries from the identification) and grains with an area less than $5 \mu \mathrm{m}^{2}$ were removed in order to avoid noise. Results are summarised in Table 3.

Table 3. Average grain size (austenite and delta ferrite) and delta ferrite content obtained by EBSD.

\begin{tabular}{|c|c|c|}
\hline Average Austenite Grain Diameter $(\boldsymbol{\mu m})$ & Average Ferrite Grain Diameter $(\boldsymbol{\mu m})$ & Ferrite content $(\boldsymbol{\%})$ \\
\hline 16.9 & 6.8 & 2.6 \\
\hline
\end{tabular}

Some inclusions (mostly intergranular) were imaged and analysed by EDX. The specific inclusion shown in Figure 1 is $\mathrm{Mn}$ and $\mathrm{S}$ rich, and most likely MnS, however a wide variety of inclusions with different chemical composition such as Al-oxides with some regions enriched in Ti, Mn and Mg, Ti-Mn, TiS, C-P and NiS are also present in the matrix. The inclusion density was quantified by thresholding multiple images of variable magnification (maximum pixel size of a thresholded image is $0.8 \mu \mathrm{m}$ ) and it was found that the inclusion coverage was typically on the order of $0.01 \%$ with a size 0 f $\sim 2 \mu \mathrm{m}$.
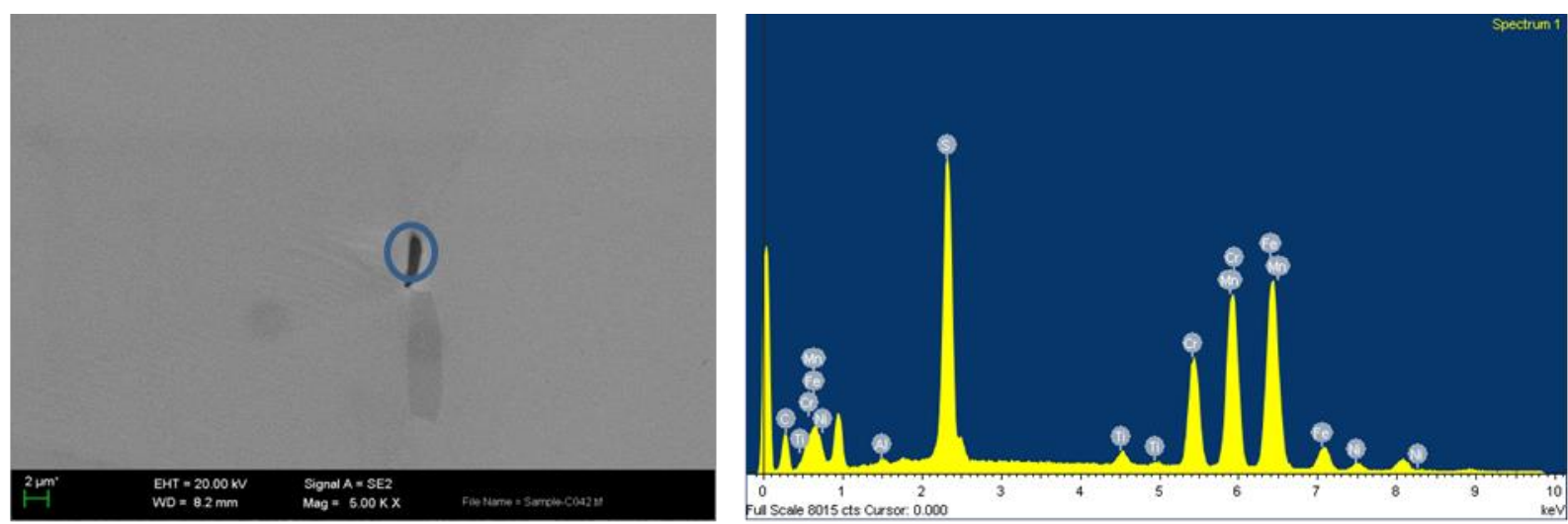

Figure 1. Left) SEM image (cross-section) of an inclusion present in the as-received material and right) EDX spectrum of the inclusion highlighted in blue at the SEM image.

\subsection{Unstressed coupon exposure tests}

Coupons were cut from the forged material and one face was 600 grit ground and the other was OPS polished. The coupons were then exposed to the high temperature $\left(300{ }^{\circ} \mathrm{C}\right)$ water environment in autoclaves for $500 \mathrm{~h}$. Oxidation of the forged material allowed for the determination of reference inner oxide thickness. A 3D-FIB reconstruction of a representative region of the material OPS surface (Figure 2) indicated that the inner oxide thickness (shown in green) varies in austenite $(300-500 \mathrm{~nm})$ and ferrite $(50-100 \mathrm{~nm})$ which allows for a visual identification (without the need of chemical composition analysis) of the $\delta-\gamma$ interface from cross-section imaging. Higher inner oxide thicknesses (>500 nm) have also been observed (Figure $2 \mathrm{c}$ and d), and are most likely due to slip bands and/or grain boundaries. 

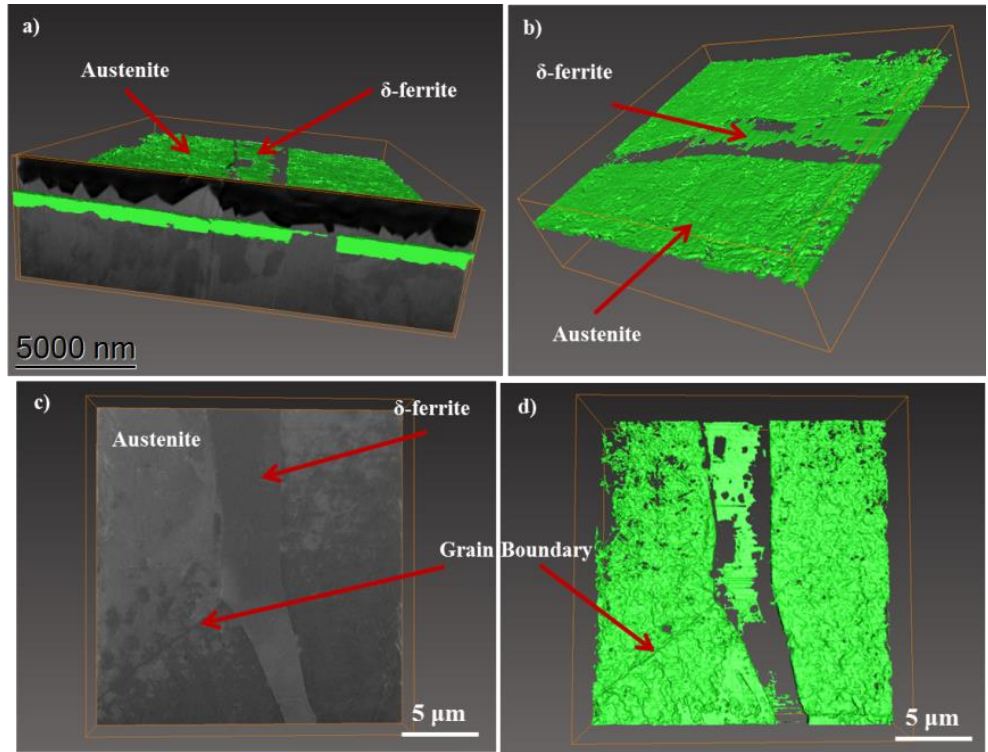

Figure 2. Oxidised forged material (OPS surface) 3D reconstruction. The combination of inner oxide surface (green) and SEM images allow the phase identification and identification of grain boundaries.

Austenite - ferrite interfaces are also easily recognizable due to differences in $\mathrm{Cr}$ and Ni content (higher content in ferrite and austenite, respectively). EELS elemental maps taken at an austenite-ferrite interface (Figure 3a and b) reveal a $\mathrm{Cr}$ enrichment (and Fe depletion) at the bottom part of the inner oxide followed by Ni enrichment at the inner oxide-metal interface. This Ni-enrichment seems to be higher at the oxide-ferrite interface than at the oxide-austenite interface. More specifically, the relative $\mathrm{Ni}$ composition (wt\%) at the oxide-ferrite interface (Figure 3c) reaches $30 \%$ whilst relative $\mathrm{Ni}$ composition (wt $\%$ ) at the oxide-austenite interface (d) reaches only $9 \%$.

a)

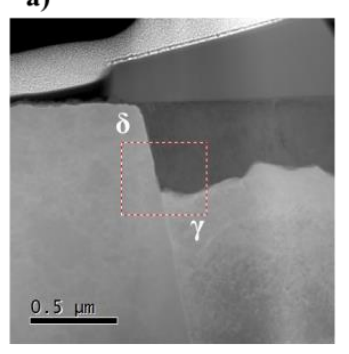

c)
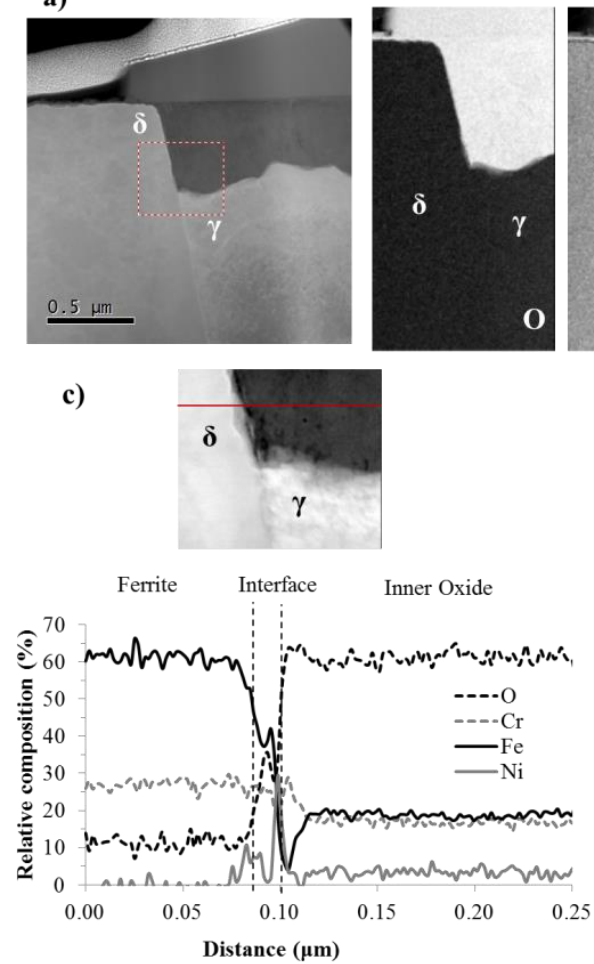

b) EELS Elemental Maps
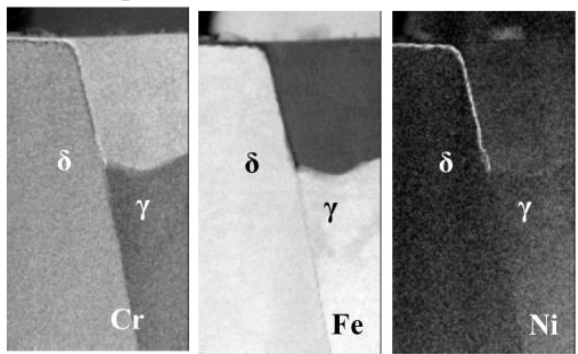

d)
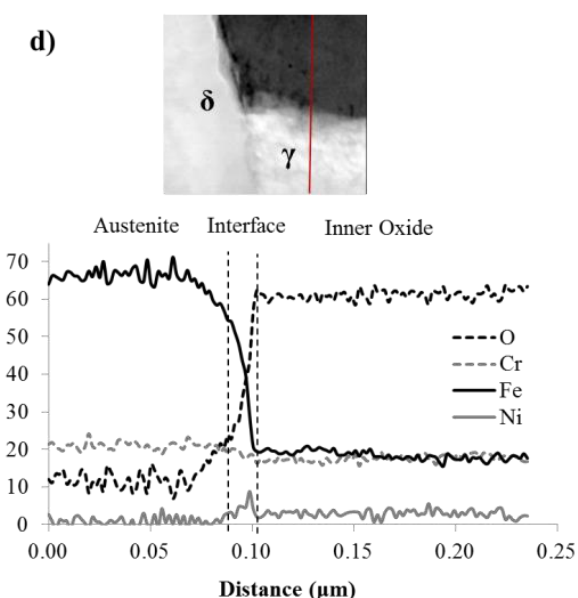

Figure 3. Oxidised forged material (OPS surface) a) STEM high angle annular dark field (HAADF) cross-section image at a delta ferrite - austenite interface, b) EELS elemental maps at the interface, c) region of interest (ROI) extracted from a) (top) and relative composition across the oxide - ferrite interface (red line) (bottom) and (d) relative composition across the oxide - austenite interface (red line) (bottom). 
Figure 3a and Figure 4a-c suggest that the inner oxide on OPS surface is compact and of uniform thickness for each phase. This is not the case for the oxide on the 600 grit surface (Figure 4d-f) which is variable in depth and not continuous. In this case, oxide thickness varies from 100 to $600 \mathrm{~nm}$ (including regions with slip bands) for austenite and $\sim 50 \mathrm{~nm}$ for ferrite.
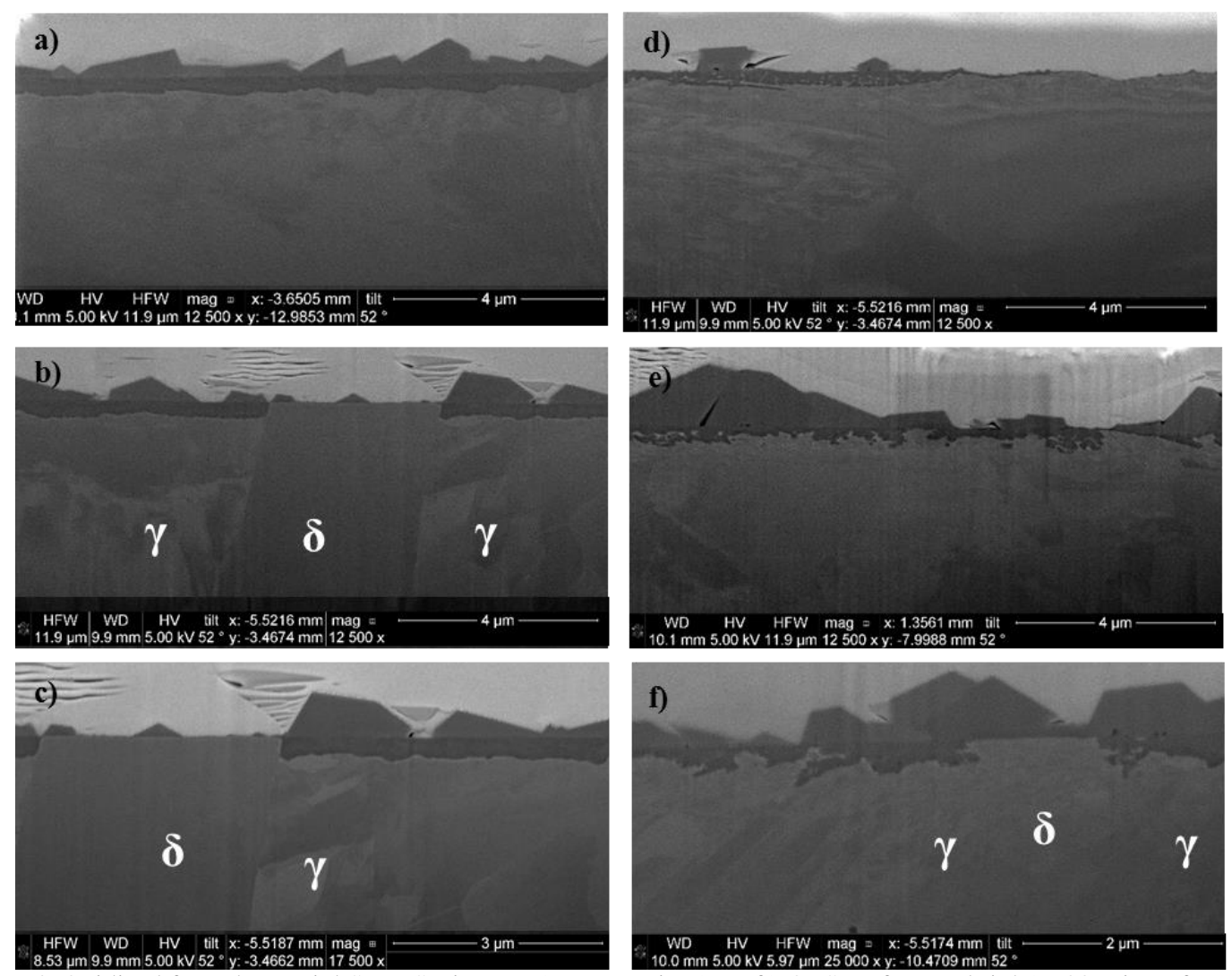

Figure 4. Oxidised forged material SEM SE images (cross-section ). Left) OPS surface and right) 600 grit surface. (a-c) illustrate the uniform thickness of the oxide at the OPS surface. Comparisons between different regions of the specimen at the 600grit surface shown in (d), (e), and (f) illustrate the variability in oxide thickness and morphology.

\subsection{C3R2C1}

A small number of crack-like features, 5-20 $\mu \mathrm{m}$ in length, were present on C3R2C1 (OPS surface) after the test (Figure 5). In many cases, they appear to be at the ferrite - austenite interface (Figure 5b). However, FIB cross-sectioning (Figure $5 \mathrm{c}$ and d) revealed the presence of inclusions associated with the cracks. These cracks widen as they grow deeper in the bulk and a porous area is found surrounding the cracks flanks. Therefore, it is likely that the cracks present in the $\mathrm{C} 3 \mathrm{R} 2 \mathrm{C} 1$ sample (1.6\% strain) are more likely to be caused by the presence of inclusions, their dissolution and just mechanical behaviour rather than SCC. 

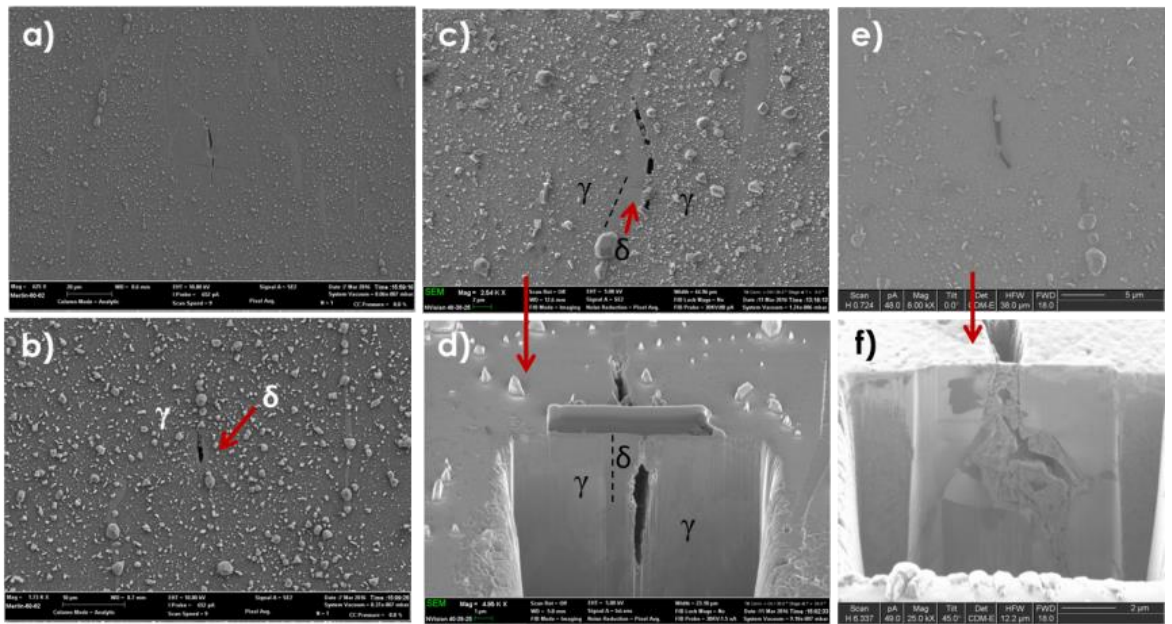

Figure 5. SEM (a - d) and FIB (e -f) images of some cracks with inclusions present at C3R2C1 (OPS). Surface view (a - c and e) and cross-section ( $\mathrm{d}$ and $\mathrm{f}$ ).

\subsection{SSRT-T2}

After $3 \%$ strain, the main crack type observed (at both OPS and 600 grit surfaces) were small cracks $(\sim 2 \mu \mathrm{m}$ in depth) that rarely penetrated into the metal. Some examples of this kind of crack are shown in Figure 6 where it is clear that they are always associated with locally deeper oxide regions (associated with deformation bands).
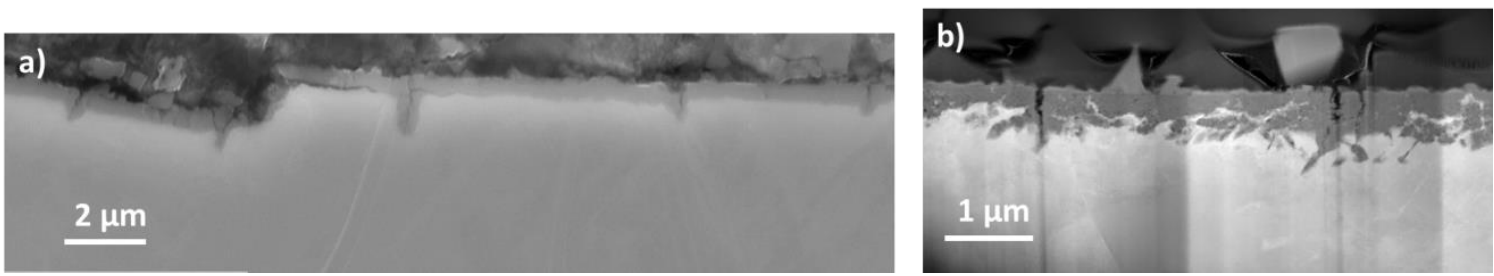

Figure 6. SSRT-T2 oxide cracking (cross-section) a) OPS surface SEM image and b) 600 grit surface STEM image.

However, deeper crack penetration into the metal is also observed on both surface finishes. Most of these deeper cracks appear to be associated with inclusions (as occurred to C3R2C1 and as shown in Figure 7), but also some of them are at $\gamma-\delta$ interfaces (Figure 8a) and $\gamma$ grain boundaries (Figure 8b). Also, cracks at the interface and austenite grain boundary do not show any signs of localized plastic deformation along the crack flanks suggesting that cracks have been initiated due to a diffusion controlled mechanism instead of just mechanical forces (purely SCC mechanism and not due to a high strain rate). On the other hand, cracks associated with inclusions have an irregular shape and crack flanks are asymmetric. In this case, crack propagation is also affected by dissolution of the inclusion. The specific inclusion associated with the crack shown in Figure 7 (apparently narrow from the surface but wider inside) is porous, containing Ti and $\mathrm{Mn}$.

In order to study the purely SCCs, several EELS elemental maps were acquired from regions of interest (as shown in Figure 8b). Two relevant maps are shown in Figure 9 which correspond to the crack tip (top) and the region close to the surface (bottom). Ahead of the crack tip, we can see some intergranular oxidation (Cr-rich oxide) $(\sim 150 \mathrm{~nm})$ and $\mathrm{Ni}$ enrichment between oxide and metal that reaches $15 \%$ (Figure 10). This $\mathrm{Ni}$ enrichment between oxide and metal is also observed at the region close to the surface and at the small crack ramifications that seem to follow grain boundaries that will reach the surface. These small cracks observed close to the main crack are likely connected in 3D with the main crack. This might not always be the case since small cracks with depths less than the inner oxide thickness have been extensively observed (Figure 6). 

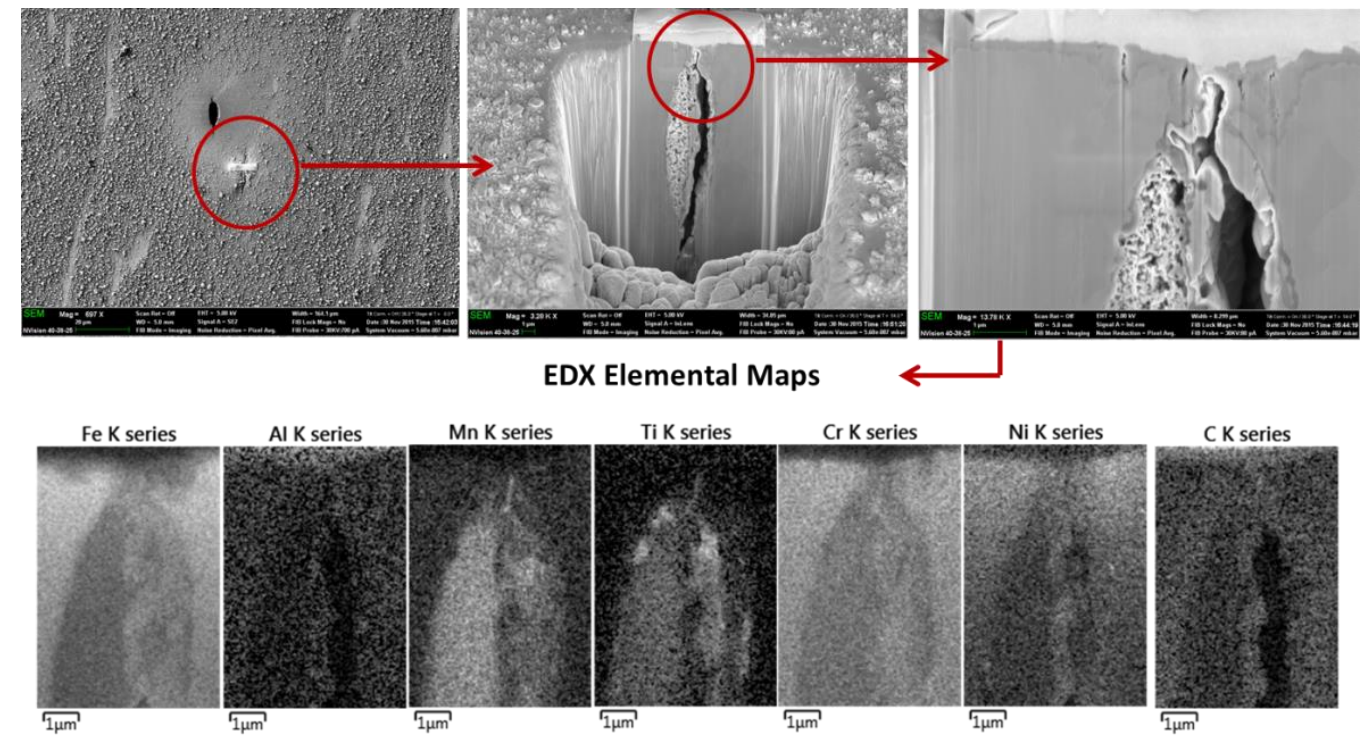

Figure 7. SSRT-T2 top) crack surface view (left), crack and inclusion cross-section (centre and right) and bottom) EDX elemental maps of the top part of the crack and inclusion.
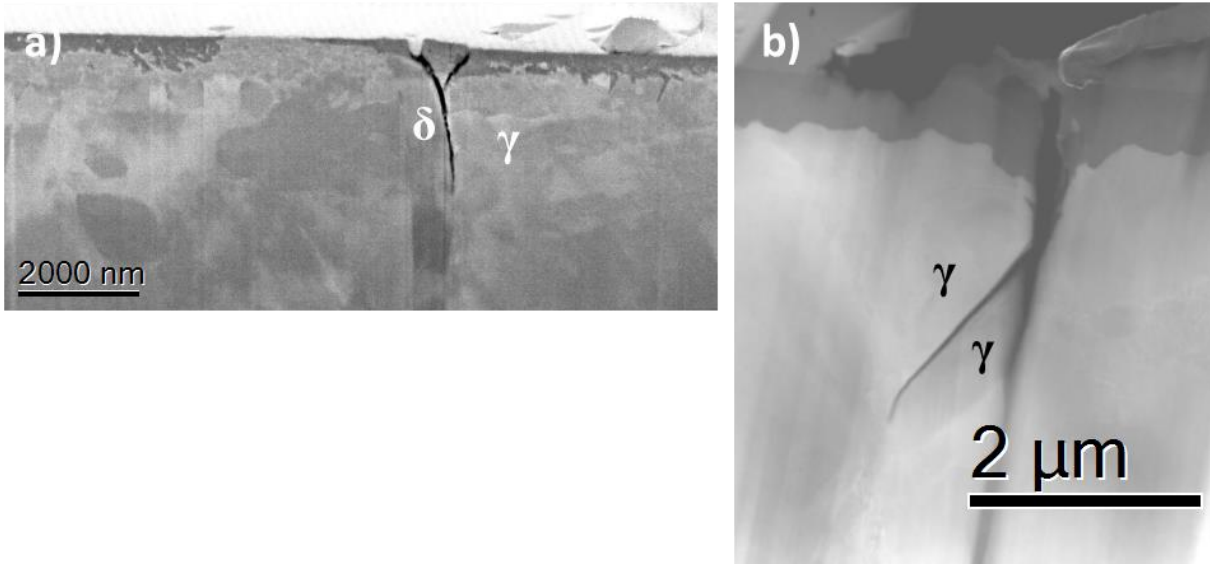

Figure 8. SSRT-T2 a) crack at the $\delta$-ferrite - austenite interface and b) intergranular crack.

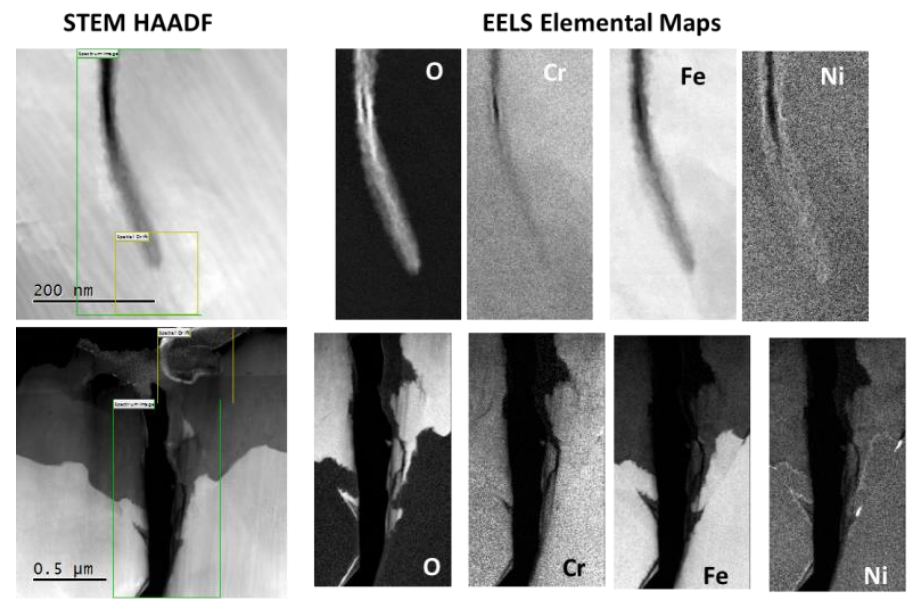

Figure 9. SSRT-T2 STEM HAADF and EELS elemental maps of intergranular crack (Figure 8) top) crack tip and bottom) region close to the surface. 

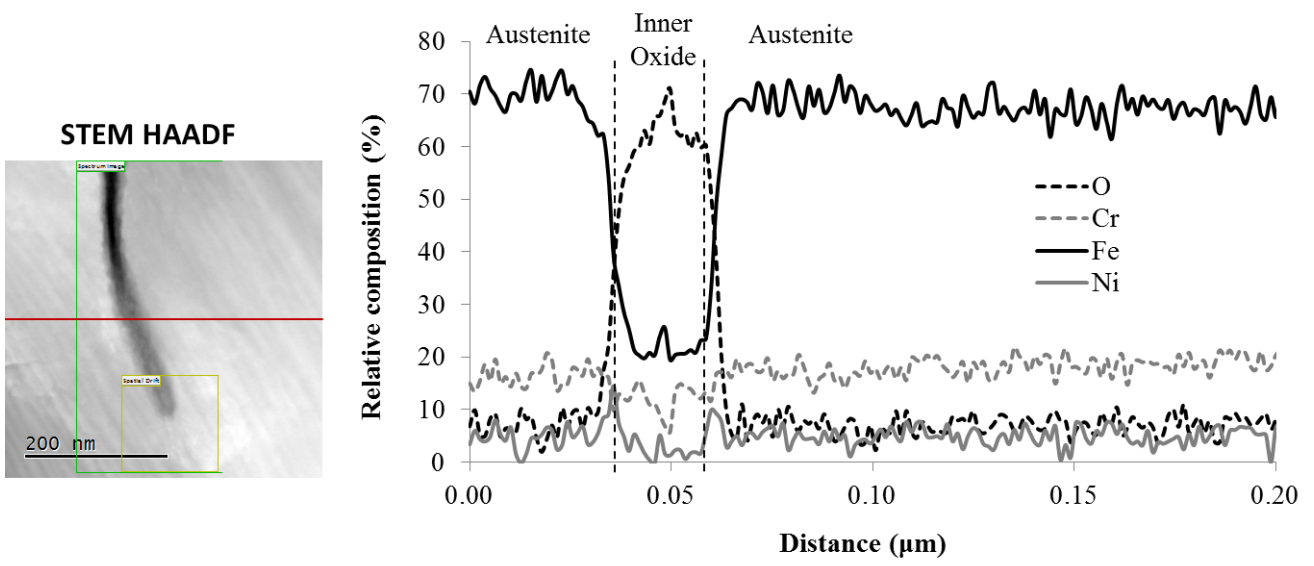

Figure 10. SSRT-T2 left) STEM HAADF image of crack tip and right) relative composition along the line highlighted in the STEM HAADF image.

TKD average misorientation and local misorientation maps (left and right, respectively) at the crack tip (Figure 11) show how the crack (white) follows the grain boundary that separates two grains $5^{\circ}$ misoriented from the average grain orientation (Figure $11 \mathrm{~b}$ green regions). Moreover, the crack reaches a triple point where it seems to stop, although oxidation tends to continue along the grain boundary with the highest deformation (measured as local matrix rotation) (Figure 11b) which is $\sim 8^{\circ}$. Local measurements (Figure 11c) confirm this region has a high concentration of dislocations (green areas).
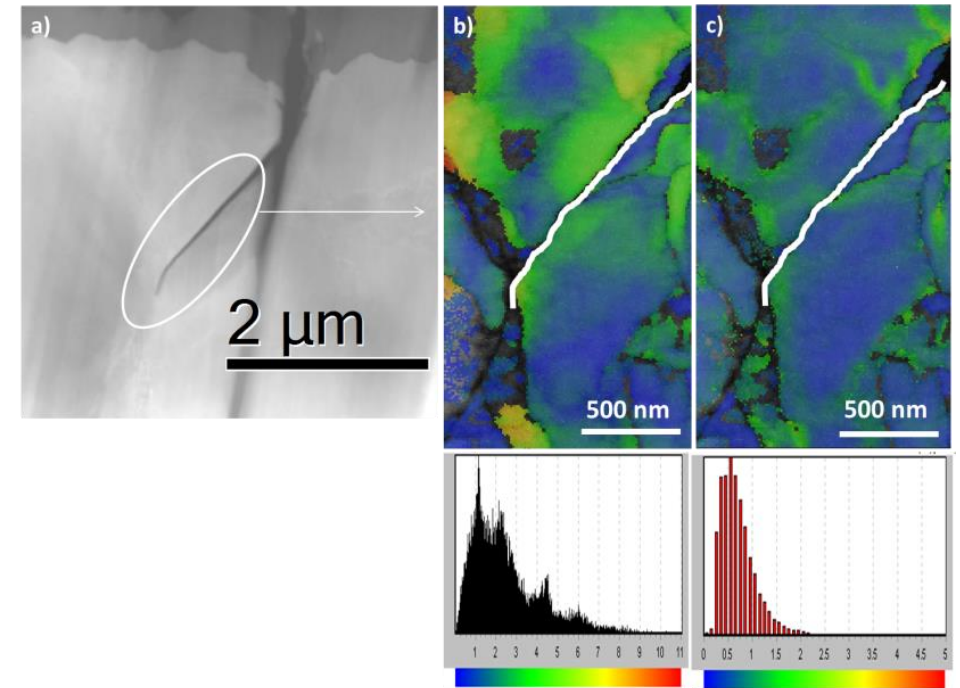

Figure 11. SSRT-T2 intergranular crack (cross-section) a) STEM image, b) average misorientation TKD map and c) KERNEL TKD map.

\subsection{SSRT-T1}

Significantly more cracking was observed in this sample after 5\% strain, than in the SSRT-T2 sample strained to $3 \%$. Most of the cracks were wide and open (from surface view) revealing their transgranular nature (Figure 12a). Moreover, cross-sectional imaging shows that most of these cracks are initially transgranular but they become intergranular or follow ferrite/austenite interfaces after some penetration (10 $\mu \mathrm{m}$, Figure 12b). However, transgranular cracks are not the only type of cracks present in the sample. Cracks at the $\delta-\gamma$ interface (Figure 12c), intergranular (Figure 12d) and surface oxide cracking (Figure 12f) have also been observed. 

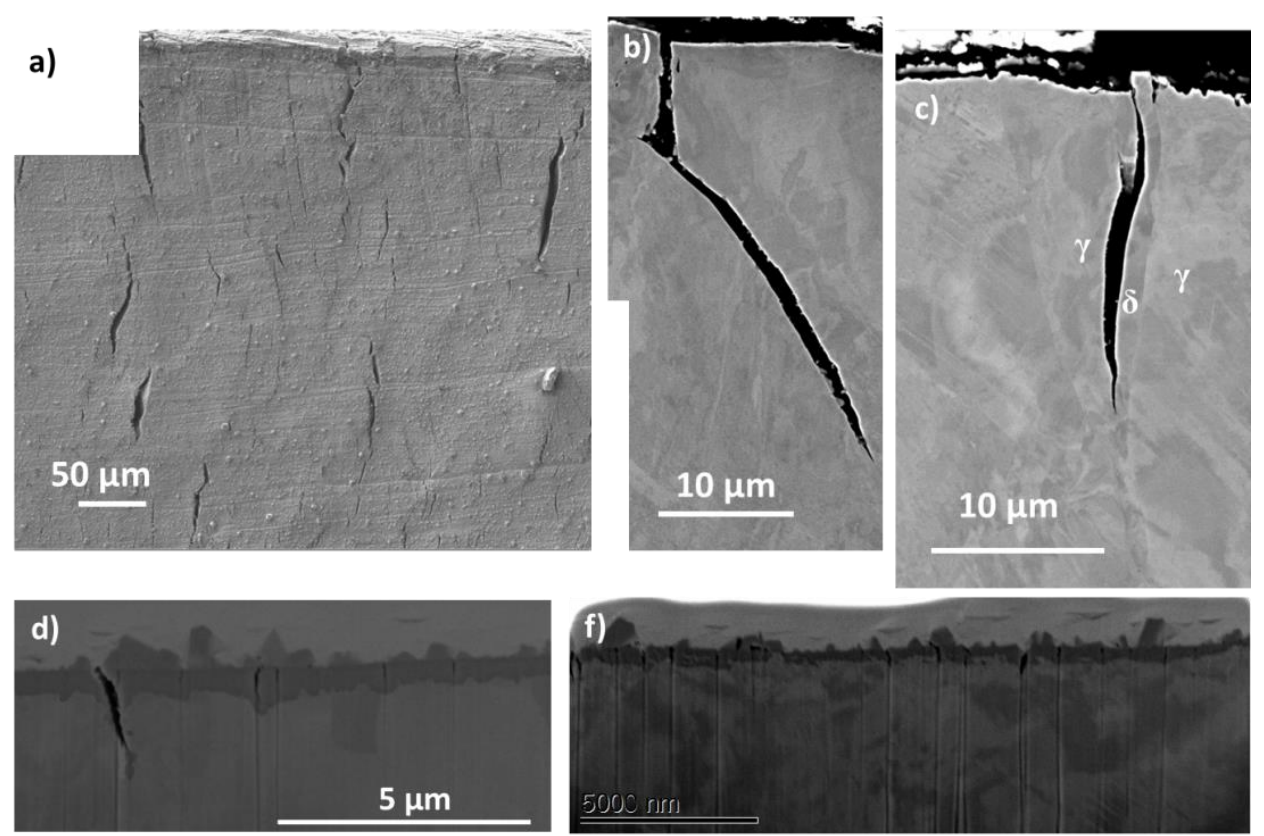

Figure 12. SSRT-T1 SEM images a) cracks viewed from the surface, b) transgranular crack that after some penetration become intergranular (cross-section), c) crack at the $\delta$ - $\gamma$ interface (cross-section), d) intergranular crack (cross-section) and f) oxide cracking (cross-section).

EDX elemental maps and STEM HAADF images of a representative transgranular crack tip are shown in Figure 13. The inner oxide at the crack flanks and tip is $\sim 10 \mathrm{~nm}$ thick and has a higher $\mathrm{Cr}$ content near the oxide-metal interface, followed by a Fe depleted and $\mathrm{Ni}$ enriched area at the interface, as already observed in the oxidised forged material and SSRT-T2. Quantitative line profiling at the very crack tip (Figure 13) shows Ni enrichment between $15-20 \%$ at the area around the oxide. Moreover, the oxide has a relative composition $60 \% \mathrm{O}, 20 \% \mathrm{Cr}$ and $20 \%$ wt. Fe, although in some areas the $\mathrm{Cr}$ content could reach $25 \%$ wt. (and consequently Fe content could decrease to $15 \%$ ).
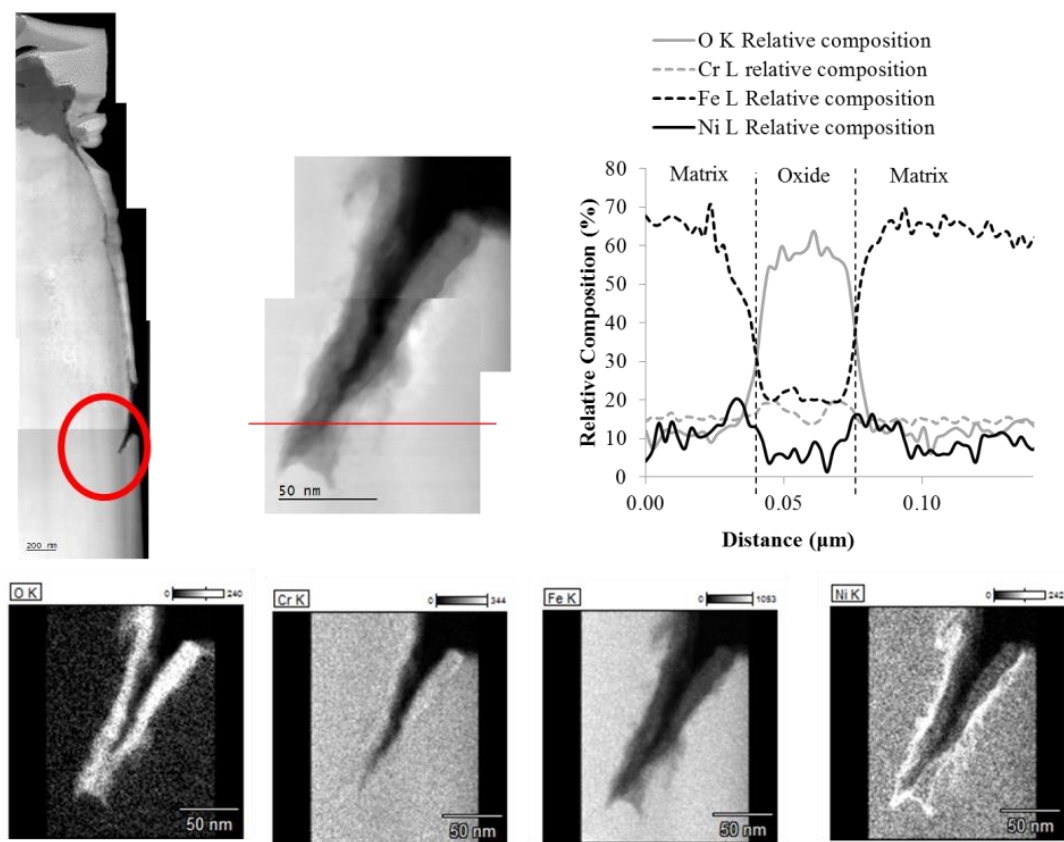

Figure 13. SSRT-T1 STEM HAADF image (cross-section) of a transgranular crack and crack tip (top left and centre, respectively), wt\% relative composition (calculated with EELS) across the red line showed in top centre image (top right) and EDX elemental maps of the crack tip (bottom). 
The average misorientation (Figure $14 \mathrm{~b}$ ) map of this particular region shows that the localisation of the most deformed area (red) corresponds with an area very close to the crack tip. This area is $12^{\circ}$ misoriented from the average grain orientation. In addition, local misorientation map (Figure $14 \mathrm{c}$ ) show the most possible propagation path. It would propagate along the region with higher concentration of dislocations (dashed white line).
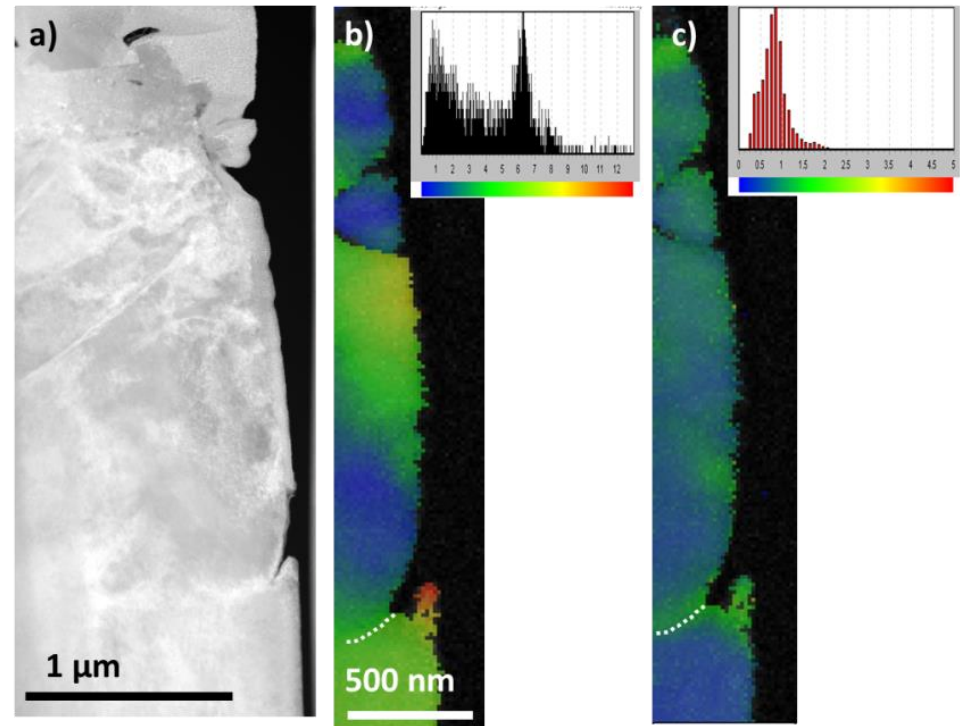

Figure 14. SSRT-T1 transgranular crack cross-section a) STEM image, b) average misorientation TKD map and c) local misorientation TKD map.

\section{DISCUSSION}

\subsection{Surface finish effects}

Samples were prepared with two surface finishing methods (600 grit and OPS) in order to determine its effect on oxidation, crack initiation and crack propagation. OPS surface finishing is more relevant to laboratory conditions whilst 600 grit surface is more similar than OPS to plant conditions.

Analysis of the effect that the surface finish has on oxidation has been determined with 3D-FIB on SSRT-T2 (3\% effective strain). A volume (one volume per surface finish) of $20 \times 20 \times 10 \mu \mathrm{m}^{2}$ was milled on a slice by slice basis in steps of $60 \mathrm{~nm}$. After each step a picture of the cross-section was taken. The slides were then aligned, drift-corrected and reconstructed on a 3D volume. After the volume reconstruction, the inner oxide of each surface finish was highlighted in base of image contrast (segmentation) and isolated. Oxide thickness were then measured (a total of 300000 measurements were performed for each surface) and the distribution of oxide thickness was plotted vs. normalised frequency for both surfaces (Figure 15). For the 600 grit surface, the most frequent oxide thickness, i.e. inner oxide mean thickness at the surface, is in the region of $150-250 \mathrm{~nm}$ whilst for OPS is $600-800 \mathrm{~nm}$. Higher thickness regions correspond to the presence of oxide at deformation bands and/or small crack flanks (300 - 500 nm for 600 grit and $1.0-1.4 \mu \mathrm{m}$ for OPS). The maximum observed thickness measurements correspond to the presence of oxide at a tip of a crack and are different for the 600 grit and OPS surfaces (700 $\mathrm{nm}$ and $3.5 \mu \mathrm{m}$, respectively). 


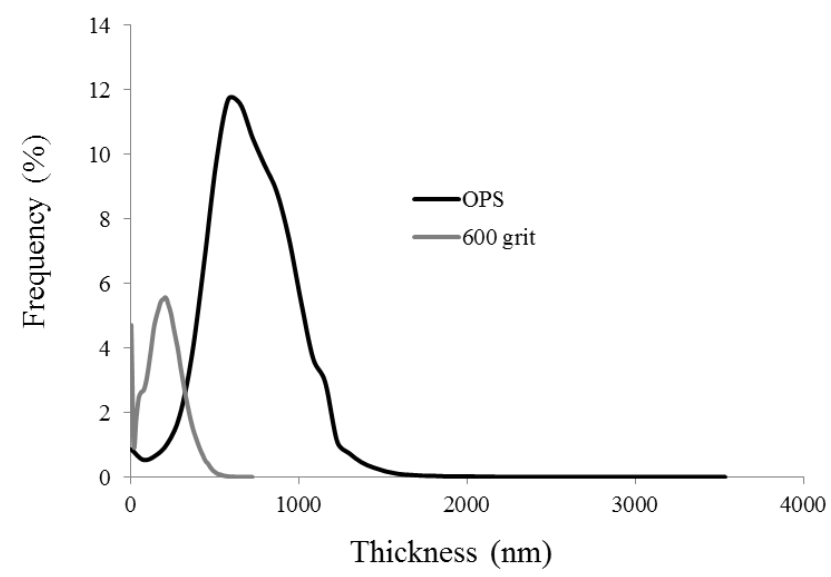

Figure 15. SSRT-T2 oxide thickness histogram. Black $=$ OPS surface and grey $=600$ grit surface.

Regarding crack initiation and propagation, 600 grit surface presents fewer initiated cracks, on both SSRT-T2 and SSRT-T1, compared to OPS surface (OPS/600 grit crack ratio=1.4 for both samples). However, crack propagation does not seem to differ much, as seen in Figure 16. There, the normalised frequency is plotted vs. crack depth and there are no remarkable differences between both surface finishing. Hence, it can be said that SCC initiation is delayed in the 600 grit surface, but once the crack propagates beyond the more deformed layer (cause by the coarser grinding), propagation behaviour (i.e. crack depth) is similar for both surfaces.
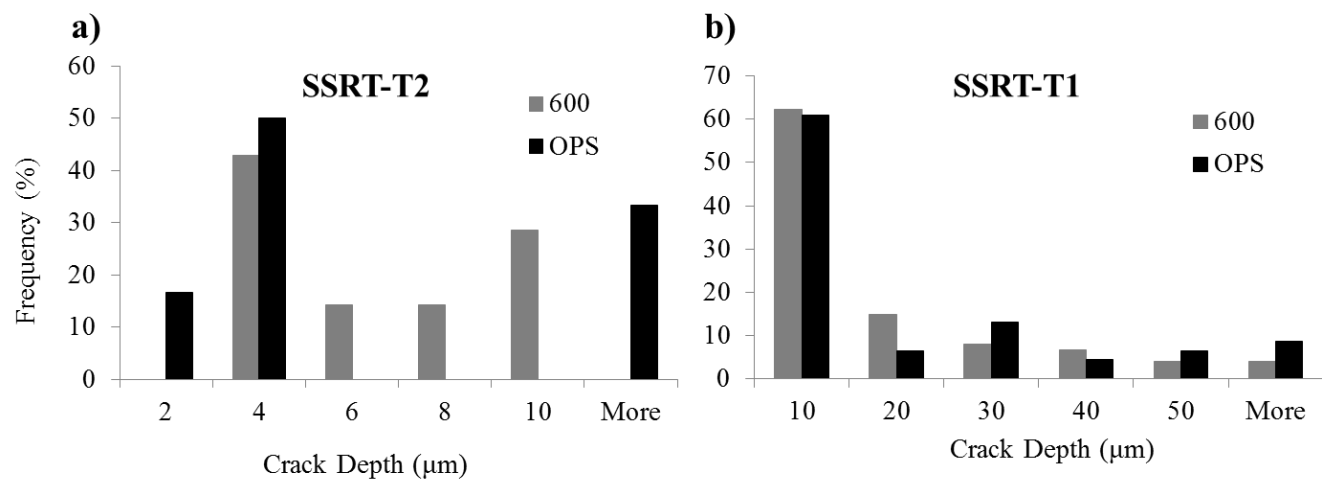

Figure 16. Crack depth histogram for OPS (black) and 600 grit (grey) surfaces a) SSRT-T2 (3\% effective strain) and b) SSRT-T1 (5\% effective strain).

\subsection{Strain effects}

3D-FIB has also been used in order to compare the effect of test conditions on the oxide thickness. Therefore, oxide thickness of SSRT-T1 (5\% effective strain and 500h) and SSRT-T2 (3\% effective strain and 900h) (both 600 grit surface) was measured (as done on section 4.1) and has been plotted vs. normalised frequency (Figure 17). In order to eliminate differences in thickness due to differences in exposure times, the data has been also normalised respect to exposure time assuming linear oxidation rate for the experimental exposure times. It can be observed that the mean oxide thickness for the sample with 5\% effective strain (SSRT-T1) is in the region of $300-500 \mathrm{~nm}$ whilst for 3\% effective strain (SSRT-T2) the most frequent oxide thickness, is $150-250 \mathrm{~nm}$. Although oxide thickness values are not exactly the same for both samples, it should be noted that the image segmentation was done based on signal intensity (i.e., image contrast). For that reason, it can be said that the thickness values are comparable for both samples. In that sense, there does not seem to be any effect on oxide thickness due to the level of plastic strain since oxide thickness at the reference material ( $0 \%$ effective strain) is also similar to SSRT-T2 (3\% effective strain) and SSRT-T1 (5\% effective strain). 


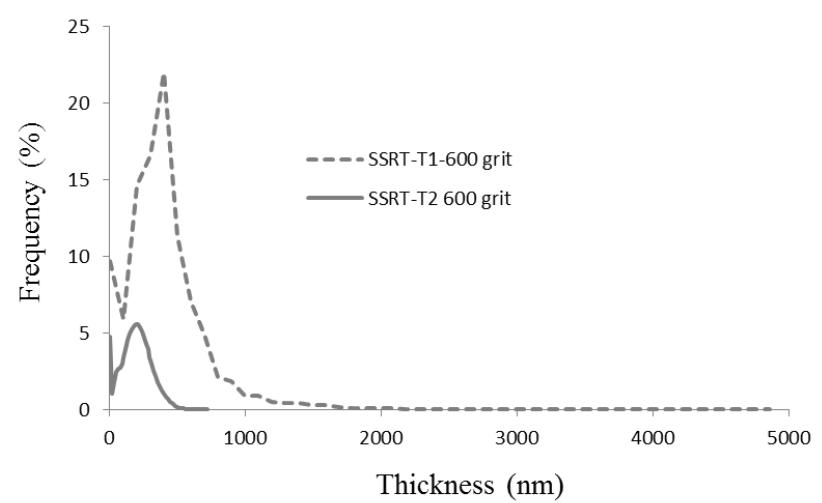

Figure 17. SSRT-T2 (600 grit surface) oxide thickness (grey) and SSRT-T1 (600 grit surface) oxide thickness (grey-dashed) histogram.

On the other hand, the different SSRT conditions applied entails, besides differences on the effective strain, differences concerning the nature, number and penetration of cracks. First of all, the main type of crack developed after the test is different, being intergranular and at the $\delta-\gamma$ interface for SSRT-T2 and intragranular for the SSRT-T1 (highest strain ratio) and, secondly, the number of cracks that effectively penetrates into the metal is ten times higher for SSRT-T1 (SSRT-T1/SSRT-T2 crack ratio=10) which depths are also considerably higher (as shown in Figure 16). Hence, SSRT-T2 strain rate conditions suggest it is experiencing the very early stages of SCC (slightly less effective strain on sample C3R2C1, that does not induce any SCC) whereas SSRTT1 strain rate conditions might be too aggressive, promoting intragranular initiation of cracks.

However, different strain rates (and consequently different effective strains) do not seem to have any correlation with diffusivity of elements. Therefore, inner oxide composition as well as $\mathrm{Ni}-\mathrm{Fe}-\mathrm{Cr}$ composition at the oxide metal interface do not differ between SSRT-T2 (Figure 9) and SSRT-T1 (Figure 13) and the reference oxidised sample (Figure 3).

\subsection{Local strain}

It is well known that ferrite is beneficial not only for retarding SCC due to its higher corrosion resistance (larger Cr content than austenite) [18] but also for exhibiting a lower crack growth rate (CGR) at the $\delta-\gamma$ interface (compared to $\gamma-\gamma$ grain boundary) [19]. However, this does not seem to be the case for the material used for this study which cracks preferentially at the ferrite - austenite interface, representing $~ 50 \%$ of the cracks in both samples (for SSRT-T1 only propagation type has be considered since most of the cracks are initially transgranular but they become intergranular or follow a $\delta-\gamma$ interface after some penetration). Based on results from Y. H. Lu et al. [20], this can be related to the sample orientation (S-L) used for this work that imply ferrite - austenite interfaces are perpendicular to stress direction, i.e., $\delta-\gamma$ interfaces are parallel to crack propagation. This stimulates higher strain localisation at the interface (therefore, more cracks) in addition to the differences accommodating stresses between ferrite and austenite.

Comparing the TKD maps of both samples (Figure 11 and Figure 14), the maximum deformation region corresponds to matrix rotations of up to $7^{\circ}$ and $12^{\circ}$ for SSRT-T2 and SSRT-T1, respectively. These values suggest that crack propagation follows a path between the two regions with the highest difference in strain localization. This also allows for a higher diffusivity (and therefore oxidation) which is expected to be stressassisted [21],[22].

\section{CONCLUSIONS}

Stress corrosion cracking initiation and propagation of 304 austenitic stainless steel have been studied at different SSRT test conditions and the following conclusions can be drawn:

1. Initiation of intergranular cracks, as well as cracks at the austenite- $\delta$-ferrite interface, occurred after $3 \%$ effective strain. Initiation of transgranular cracks takes place at 5\% effective strain. These transgranular cracks become intergranular at the $\delta-\gamma$ interface after some penetration. 
2. Oxide thickness after SSRT tests does not seem to be affected for the different test conditions between SSRT-T1 $\left(2.5 \times 10^{-8}\right.$ strain rate, $5 \%$ effective strain and 500h) and SSRT-T2 $\left(1.0 \times 10^{-8}\right.$ strain rate, $3 \%$ effective strain and $900 \mathrm{~h}$ ) although it is affected by the surface finishing. Inner oxide on the austenite at the OPS surface is continuous and compact whilst the inner oxide at the 600 grit surface is very variable in depth and not compact.

3. Surface finishing also affects the number of cracks initiated. The number of cracks initiated on the 600 grit surface is lower compared to the more finely polished OPS surface; however, once initiated, crack depth is similar for both surfaces.

4. Different effective strains do not seem to have any correlation with diffusivity of elements. Therefore, the inner oxide composition as well as Ni-Fe-Cr composition at the oxide - metal interface do not differ between SSRT-T2 (3\% strain) and SSRT-T1 (5\% strain).

5. Both SSRT-T2 (3\% strain) and SSRT-T1 (5\% strain) contain a large number of cracks at the ferriteaustenite interface. This is attributed to the sample orientation (S-L) selected for the tests for which these phase interfaces are parallel to the crack propagation direction. This orientation may stimulate higher strain localisation at the interface in addition to the stress incompatibility between the ferrite and austenite..

\section{REFERENCES}

[1] K. Arioka, T. Yamada, T. Terachi, R.W. Staehle, "Intergranular stress corrosion cracking behavior of austenitic stainless steels in hydrogenated high-temperature water", Corrosion, 62 (2006), 74-83.

[2] K. Arioka, T. Yamada, T. Terachi, G. Chiba, "Cold work and temperature dependence of stress corrosion crack growth of austenitic stainless steels in hydrogenated and oxygenated high-temperature water", Corrosion, 63 (2007), 1114-1123.

[3] T. Terachi, T. Yamada, T. Miyamoto, K. Arioka, K. Fukuya, K, "Corrosion behaviour of stainless steels in simulated PWR primary water-effect of chromium content in alloys and dissolved hydrogen", Journal of Nuclear Science and Technology, 45 (2008), 975-984.

[4] R.W. Staehle, "Critical analysis of "tight cracks", 13th International Conference on Environmental Degradation of Materials in Nuclear Power Systems 2007, 3 (2007), 1877-1957.

[5] S.M. Bruemmer, M.J. Olszta, M.B. Toloczko, L.E. Thomas, "Linking grain boundary microstructure to stress corrosion cracking of cold-rolled alloy 690 in pressurized water reactor primary water", Corrosion, 69 (2013), 953-963.

[6] S. Lozano-Perez, J. Dohr, M. Meisnar, K. Kruska, "SCC in PWRs: Learning from a bottom up approach", Metallurgical and Materials Transactions E, 1 (2014), 194-210.

[7] L.E. Thomas, S.M. Bruemmer, "High-Resolution characterization of intergranular attack and stress corrosion cracking of Alloy 600 in high-temperature primary water”, Corrosion, 56 (6) (2000), 572-587.

[8] S. Lozano-Perez, J.M. Titchmarsh, "TEM investigations of intergranular stress corrosion cracking in austenitic alloys in PWR environmental conditions", Materials at High Temperature, 20 (4) (2003), 573579.

[9] K. Kruska, S. Lozano-Perez, D.W. Saxey, T. Terachi, T. Yamada, G.D.W. Smith, "3D atom-probe characterization of stress and cold-work in stress corrosion cracking of 304 stainless steel", 15th International Conference on Environmental Degradation of Materials in Nuclear Power Systems-Water Reactors, 2 (2011), 891-898.

[10] S. Lozano-Perez, L.C. Gontard, "Understanding stress corrosion cracking with electron tomography", Microscopy and Microanalysis, 14 (2008), 642-643.

[11] S. Lozano-Perez, M.R. Kilburn, T. Yamada, T. Terachi, C.A. English, C.R.M. Grovenor, "High-resolution imaging of complex crack chemistry in reactor steels by NanoSIMS", Journal of Nuclear Materials, 374 (2008), 61-68.

[12] M. Meisnar, A. Vilalta-Clemente, A. Gholinia, M. Moody, A. J. Wilkinson, N. Huin, S. Lozano-Perez, "Using transmission Kikuchi diffraction to study intergranular stress corrosion cracking in type 316 stainless steels", Micron, 75 (2015) 1-10. 
[13] M. Meisnar, A. Vilalta-Clemente, M. Moody, K. Arioka, S. Lozano-Perez, "A mechanistic study of the temperature dependence of the stress corrosion crack growth rate in SUS316 stainless steels exposed to PWR primary water, Acta Materialia, 114 (2016), 15-24.

[14] B. Schaffer, W. Grogger, G. Kothleitner, "Automated Spatial Drift correction for EFTEM Image series", Ultramicroscopy, 102 (1) (2004), 27-36.

[15] S. Lozano-Perez, V. de Castro Bernal, R.J. Nicholls, "Achieving sub-nanometre particle mapping with energy-filtered TEM”, Ultramicroscopy, 109 (10) (2009), 1217-1228.

[16] M. Bosman, M. Watanabe, D.T.L. Alexander, V.J. Keast, "Mapping chemical and bonding information using multivariate analysis of electron energy-loss spectrum images" Ultramicroscopy, 106 (11-12) (2006), 1024-1032.

[17] F. de la Peña, M.-H. Berger, J.-F. Hochepied, F. Dynys, O. Stephan, M. Walls, "Mapping titanium and tin oxide phases using EELS: An application of independent component analysis", Ultramicroscopy, 111, (2) (2011), 169-176.

[18] V.S. Raja, T. Shoji, Stress Corrosion Cracking: Theory and practice (UK: Woodhead Publishing Limited 2011) 220.

[19] H. Abe, Y. Watanabe, "Role of $\delta$-ferrite in stress corrosion cracking retardation near fusion boundary of 316NG welds", Journal of Nuclear Materials, 424 (2012), 57-61.

[20] Y. H. Lu, Z. R. Chen, X. F. Zhu, T. Shoji, "SCC behaviours of austenitic stainless steel Z3CN20-09M in high temperature water", Materials Science and Technology, 30 (15) (2014), 1944-1950.

[21] S. Lozano-Perez, T. Yamada, T. Terachi, M. Schröder, C.A. English, G.D.W. Smith, C.R.M. Grovenor, B.L. Eyre, "Multi-scale characterization of stress corrosion cracking of cold-worked stainless steels and the influence of Cr content", Acta Materalia, 57 (2009), 5361-5381.

[22] S. Lozano-Perez, K. Kruska, I. Iyengar, T. Terachi, T. Yamada, "The role of cold work and applied stress on surface oxidation of 304 stainless steel”, Corrosion Science, 56 (2012), 78-85.

\section{ACKNOWLEDGEMENTS}

EELS data were acquired with JEOL ARM200 microscope funded by the EPSRC, grant $\mathrm{EP} / \mathrm{K} 040375 / 1$. 